\title{
ARTICLE
}

\section{Annonaceous acetogenin mimic AA005 suppresses human colon cancer cell growth in vivo through downregulation of Mcl-1}

\author{
Bing Han ${ }^{1,2}$, Yu-xia Cao ${ }^{3}$, Zhan-ming $\mathrm{Li}^{1,2}$, Zhao-xia Wu ${ }^{1,2}$, Yu-qin Mao ${ }^{1,2}$, Hui-ling Chen ${ }^{1,2}$, Zhu-jun Yao ${ }^{4}$ and Li-shun Wang ${ }^{1,2}$
}

\begin{abstract}
Annonaceous acetogenins are a well-established family of natural products with significant bioactivities, especially high cytotoxic and antitumor activities. AA005 is an annonaceous acetogenin mimic that has shown significant cytotoxicity against a variety of cancer cell lines, but its in vivo antitumor effects have not been demonstrated so far, and its anticancer mechanisms remain ambiguous. In this study, we investigated the effects of AA005 on human colon cancer cell lines in vivo. Human colon carcinoma cell line SW620 xenograft nude mice were treated with AA005 (5 mg/kg/day, i.p.) for 21 days. AA005 administration markedly inhibited the tumor growth via promoting nuclear translocation of apoptosis-inducing factor (AIF) and inducing AIF-dependent cell death. Subsequent studies in human colon carcinoma cell lines SW620 and RKO in vitro revealed that after the colon cancer cells exposed to AA005, downregulation of a B-cell lymphoma 2 family protein, myeloid cell leukemia-1 (Mcl-1), was an early event due to the inhibition of $\mathrm{Mcl}-1$ mRNA level and protein synthesis in a time-dependent manner. Intriguingly, knockdown of Mcl-1 using small interfering RNA markedly accelerated the nuclear translocation of AIF and upregulation of receptor interacting protein-1, and enhanced AA005-mediated lethality, whereas ectopic expression of Mcl-1 substantially attenuated AA005-mediated lethality in the colon cancer cells. Finally, silencing Mcl-1 expression markedly enhanced AA005-induced lethality in SW620 xenograft nude mice, demonstrating a pivotal role of $\mathrm{Mcl}-1$ downregulation in mediating the in vivo antitumor effects of AA005. Taken together, this study demonstrates for the first time the anticancer effects of AA005 against human colon cancer cell lines in vivo, which is mediated through the downregulation of Mcl-1.
\end{abstract}

Keywords: AA005; AIF; cell death; colon cancer; Mcl-1

Acta Pharmacologica Sinica (2019) 40:231-242; https://doi.org/10.1038/s41401-018-0025-7

\section{INTRODUCTION}

Annonaceous acetogenins are a well-established family of natural products with significant bioactivities, especially high cytotoxic and antitumor activities [1, 2]. Over the past few years, Yao and coworkers [3] successfully developed a series of annonaceous acetogenin mimetics, and more interestingly, they found that some of these analogs have significant selectivity between human cancer cells and normal cells. In the current study, a new annonaceous acetogenin mimic, AA005, showed satisfactory selectivity and also the best antitumor activity against several human cancer cell lines among a set of mimetics of annonaceous acetogenin [4-7]. However, toxicity studies and the in vivo antitumor effects of AA005 have not been investigated thus far, creating an obstacle to its further development as a leading drug.

Evidence supports that AA005 co-localizes with the mitochondria, can activate AMP-activated protein kinase and inhibit the mTOR complex 1 signal pathway, leading to growth inhibition and autophagy of cancer cells [8]. However, little is known of other signaling pathways involved in the regulation of AA005-induced cancer cell death. Interestingly, our recent study indicated that
AA005 could induce apoptosis-inducing factor (AIF)-dependent but caspase-independent cell death [7]. However, the intrinsic cell death signaling that triggers AIF translocation to cause AA005induced cell death remains ambiguous. In this work, we further clarify the molecular mechanisms of AA005 killing of cancer cells.

Stress-induced cell death in mammalian cells is regulated by the B-cell lymphoma $2(\mathrm{Bcl}-2)$ family proteins through a series of orderly events in which mitochondrial outer membrane permeabilization (MOMP) is critical. It appears that the pro-apoptotic family members Bax and Bak are crucial to inducing permeabilization of the outer mitochondrial membrane and the subsequent release of apoptogenic molecules such as cytochrome $c$, DIABLO, and AIF [9-12]. Anti-apoptotic family members such as Bcl-2 and B-cell lymphoma-extra large (Bcl-xL) inhibit Bax and Bak [13-15]. Myeloid cell leukemia-1 (Mcl-1) is also an anti-apoptotic Bcl-2 family protein frequently overexpressed or amplified in human cancers [16-18]. A number of recent studies suggest a critical role of $\mathrm{Mcl}-1$ in tumor cell survival and therapeutic resistance $[17,19]$. Selective overexpression of $\mathrm{Mcl}-1$ in hematopoietic tissues of transgenic mice promotes the survival of hematopoietic cells and

\footnotetext{
${ }^{1}$ Minhang Branch, Zhongshan Hospital, Fudan University, 201199 Shanghai, China; ${ }^{2}$ Institute of Fudan-Minhang Academic Health System, Minhang Hospital, Zhongshan Hospital, Fudan University, 201199 Shanghai, China; ${ }^{3}$ Internal Medicine Department, Jinan Central Hospital, 250013 Jinan, China and ${ }^{4}$ State Key Laboratory of Coordination Chemistry, School of Chemistry and Chemical Engineering, Nanjing University, 210093 Nanjing, China

Correspondence: Zhu-jun Yao (sioc-yzj@163.com) or Li-shun Wang (lishunwang@fudan.edu.cn)
}

Received: 18 January 2018 Revised: 24 March 2018 Accepted: 28 March 2018

Published online: 19 June 2018 
enhances the outgrowth of myeloid cell lines [20]. Mcl-1 downregulation is often sufficient to promote apoptosis in cancer cells, suggesting that $\mathrm{Mcl}-1$ could be a potential therapeutic target in the treatment of several human cancers [19, 21-23]. RIP kinases constitute a family of seven members, i.e., RIP1-7, that includes serine threonine kinases as crucial regulators of cell survival and cell death. Indeed, the kinase receptor interacting protein-1 (RIP-1) has been implicated in the regulation of apoptosis [24] and necroptosis [25].

In this study, we report for the first time that AA005 exhibits in vivo antitumor activity by induction of cell death, which is mediated by downregulation of $\mathrm{Mcl}-1$. The results indicate that AA005 downregulates Mcl-1 expression through inhibition of the transcriptional and translational mechanism. Furthermore, knockdown of $\mathrm{Mcl}-1$ accelerates AIF translocation and upregulation of RIP-1 and enhances AA005-mediated lethality, whereas ectopic expression of $\mathrm{Mcl}-1$ substantially attenuates AA005-mediated lethality in these cells. Our in vivo results indicate that silencing of $\mathrm{Mcl}-1$ expression markedly inhibits tumor growth and enhances AA005-induced lethality, thus demonstrating a pivotal role of $\mathrm{Mcl}-1$ downregulation in mediating the antitumor effects of AA005. This study further elucidates the mechanism of AA005 as an antitumor agent and offers novel therapeutic clues for treating colon cancers.

\section{MATERIALS AND METHODS}

\section{Chemicals and reagents}

Annonaceous acetogenin mimic AA005 (kindly supplied by the State Key Laboratory of Coordination Chemistry, Nanjing University, Nanjing, China) was dissolved in dimethylsulfoxide as a 5 $\mathrm{mM}$ stock solution and was stored at $-80^{\circ} \mathrm{C}$. Antibodies against AIF, Lamin B, Cox IV, Mcl-1, Bcl-2, Bcl-xL, Bax, and actin were purchased from Cell Signaling Technology (Beverly, MA, USA).

\section{Cell culture and treatments}

Human colon carcinoma cell lines SW620 and RKO were purchased from American Type Culture Collection (ATCC, Manassas, VA, USA) and cultured in RPMI-1640 medium (Hyclone, Logan, UT, USA) supplemented with $10 \%$ heat-inactivated fetal bovine serum (Sigma-Aldrich, St. Louis, $\mathrm{MO}, \mathrm{USA}$ ) in a $5 \% \mathrm{CO}_{2}$ humidified atmosphere at $37^{\circ} \mathrm{C}$. For experiments, cells were seeded at $2-5 \times 10^{5}$ cells $/ \mathrm{mL}$ and incubated with or without the indicated concentrations of AA005.

\section{Animal experiments}

Animal care and experiments were performed in strict accordance with the "Guide for the Care and Use of Laboratory Animals" and "Principles for the Utilization and Care of Vertebrate Animals" and were approved by the committee for humane treatment of animals at Shanghai Jiao Tong University School of Medicine. Nude mice (5 weeks old) were purchased from Shanghai Model Organisms Center, Inc. (Shanghai, China). SW620 cells and shNC or shMcl-1 SW620 cells ( $1 \times 10^{6} / 0.2 \mathrm{~mL}$ per mouse) were suspended in sterile PBS and injected subcutaneously into the mice. Seven days after tumor inoculation, the treatment group received AA005 $(5 \mathrm{mg} / \mathrm{kg})$ intraperitoneally for 21 days. The control group received an equal volume of solvent control. Tumor size and body weight were measured every day. Tumor volumes were determined by caliper and calculation according to the formula (width ${ }^{2} \times$ length)/2. All animals were killed immediately after 21 days of drug exposure.

\section{Immunohistochemical staining}

Immunohistochemical (IHC) staining was applied to detect the protein levels of $\mathrm{Mcl}-1$ and subcellular localization of AIF between different tumor tissues with anti-Mcl-1 (Abcam, Cambridge, MA, USA, ab32087) or anti-AIF (Cell Signaling Technology, Danvers, MA, USA, \#4642) antibodies. IHC staining was performed according to the manufacturer's protocol.
Subcellular cell fractionation and mitochondria purification Cells were separated into different fractions according to previously described methods [26, 27]. In brief, cells were harvested and rinsed with mitochondria isolation buffer (MIB, $0.25 \mathrm{M}$ sucrose and $10 \mathrm{mM}$ Tris $-\mathrm{HCl}, \mathrm{pH} 7.4)$, resuspended in MIB supplemented with $1 \%$ protease inhibitor cocktail and homogenized using a glass Dounce homogenizer (Kontes, Sigma-Aldrich) with 20 strokes at $4{ }^{\circ} \mathrm{C}$. The homogenate was centrifuged at $1000 \times \mathrm{g}$ for $10 \mathrm{~min}$ to pellet the nucleus. The supernatant was centrifuged at $15,000 \times \mathrm{g}$ for $20 \mathrm{~min}$ at $4{ }^{\circ} \mathrm{C}$ to pellet the raw mitochondria. Cytoplasmic proteins in the postmitochondria supernatant were precipitated with chloroform and methanol according to Klotz's methods [28]. To further enrich the mitochondria, the pellet of raw mitochondria was resuspended in 36\% iodixanol (Sigma-Aldrich) and overlaid with 30 and $10 \%$ iodixanol. The gradient was ultracentrifuged $(80,000 \times g, 3 \mathrm{~h})$ at $4{ }^{\circ} \mathrm{C}$. The purified mitochondria ere collected at the interface between 10 and $30 \%$ iodixanol and washed twice with MIB. Samples of each fraction were prepared by addition of sample buffer and subjected to immunoblot analysis.

\section{Western blots}

Cells were rinsed with ice-cold $1 \times P B S$ and lysed in nonreducing buffer containing $100 \mathrm{mM}$ Tris- $\mathrm{HCl}, \mathrm{pH} 6.8,2 \%$ SDS, 50 mM IAA, supplemented with PMSF and cocktail, or reducing buffer containing an additional $100 \mathrm{mM}$ DTT. Cell lysates were separated on a $8-12.5 \%$ SDS-polyacrylamide gel, transferred to a nitrocellulose membrane (Bio-Rad, Richmond, CA), blocked with $5 \%$ nonfat milk in PBS, and immunoblotted with the indicated antibodies. After incubation with the horseradish peroxidase-linked second antibody (Cell Signaling, Beverly, MA, USA) at room temperature, detection was performed using the SuperSignal West Pico Chemiluminescent Substrate Kit (Pierce, Rockford, IL) according to the manufacturer's instructions.

Apoptosis assay

Apoptotic cells were measured by staining with FITC-conjugated Annexin-V/propidium iodide (PI) (BD Pharmingen, San Diego, CA, USA) and determination via flow cytometer according to the manufacturer's instructions, as described previously [29]. Both early apoptotic (Annexin-V-positive, PI-negative) and late apoptotic (Annexin-V-positive and PI-positive) cells were included in cell death determinations.

\section{TUNEL assay}

Cells were seeded in 6-well plates 1 day prior to treatments. Apoptosis in tumor tissue sections was determined using the In Situ Cell Death Detection kit (Roche, Mannheim, Germany). In brief, tumor tissue sections of formalin-fixed paraffin-embedded specimens were dewaxed in xylene and rehydrated in a graded series of ethanol. The tumor samples were incubated with proteinase $\mathrm{K}(2 \mathrm{mg} / \mathrm{mL})$, and the TdT mediated dUTP-biotin nickend labeling (TUNEL) staining was performed according to the manufacturer's instructions.

Real-time quantitative RT-PCR

Total RNA from the cell lines were extracted with TRIzol reagent (Invitrogen, Carlsbad, CA) and treated with RNase-free DNase (Promega, Madison, WI, USA). Quantitative real-time PCR was performed using the SYBR Green PCR Master Mix (Applied Biosystems, Foster City, CA, USA). The primers used are listed as follows: Mcl-1-5'- GTGCCTTTGTGGCTAAACACT-3'(forward), 5'-AGTCCCGTITGTCCTTACGA-3'(reverse), with $\beta$-actin-5'-CATCCTCACCCTGAAGTACCC-3' (forward), 5'-AGCCTGGATAGCAACGTACATG$3^{\prime}$ (reverse). Real-time RT-PCR was performed, and the data were analyzed according to a previous report [30]. 

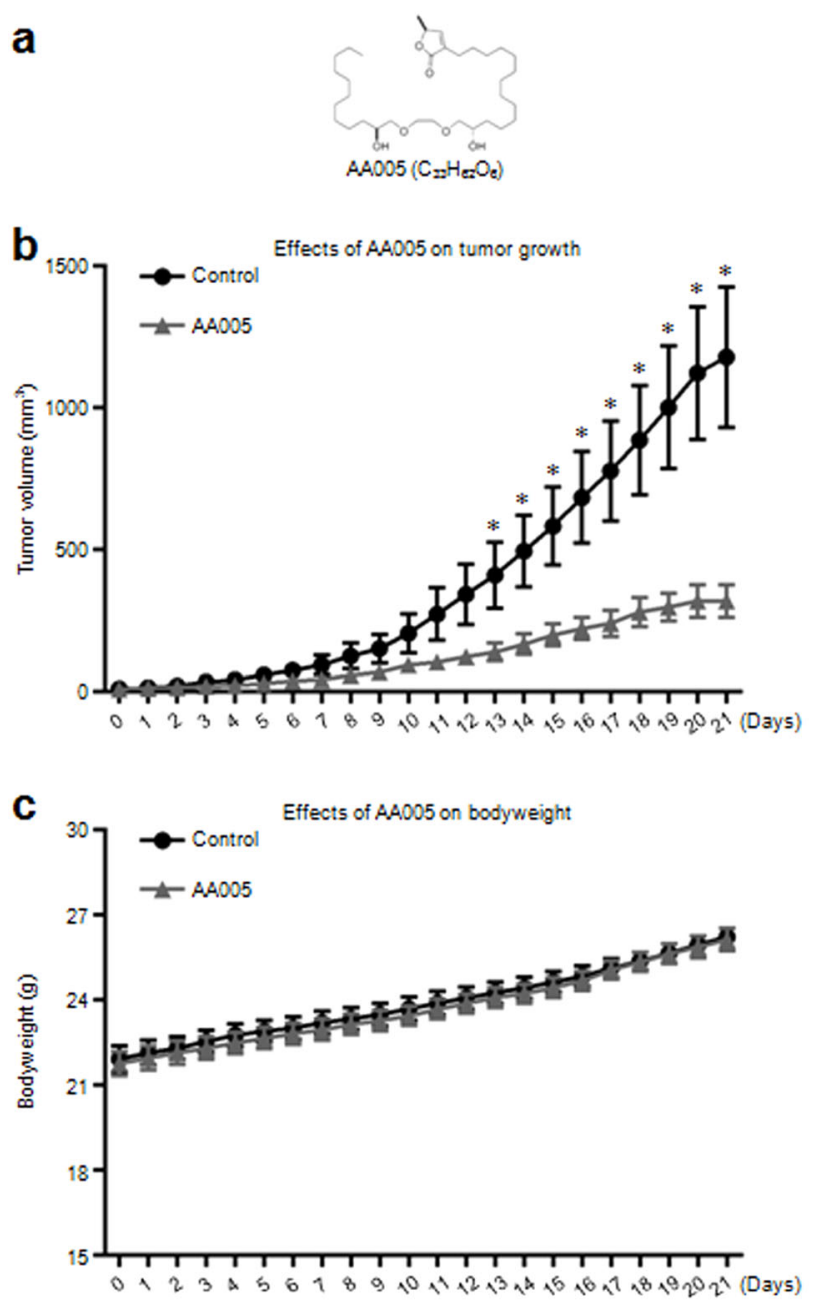

d

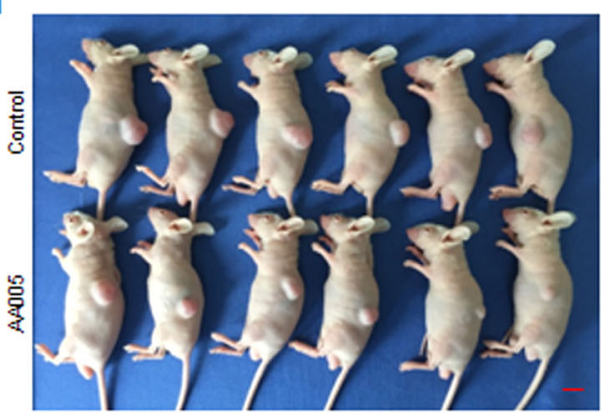

e

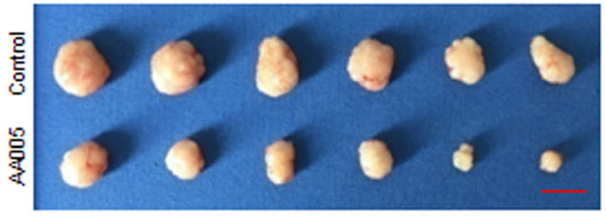

f

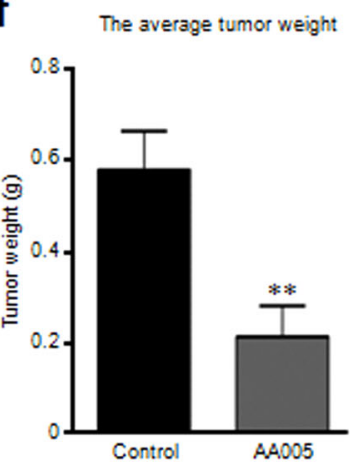

g The average inhibitory

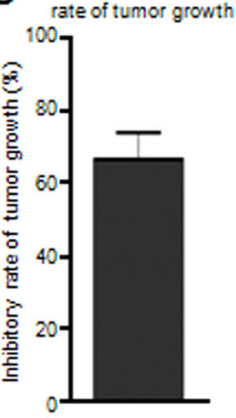

Fig. 1 AA005 exhibits antitumor activity in the xenograft animal model. a Structure of compound AA005. b 5-week-old nude mice inoculated subcutaneously with SW620 cells $\left(1 \times 10^{6} / 0.2 \mathrm{~mL}\right.$ per mouse). After 1 week, mice were treated with $5 \mathrm{mg} / \mathrm{kg}$ AA005 daily (intraperitoneally) or with the vehicle control for 21 consecutive days, and the tumor volumes were calculated (6 mice per group). c Body weight of mice. d Photograph of tumors in nude mice at the end of the experiment. Scale bars, $1 \mathrm{~cm}$. e Tumors of each group when nude mice were killed. Scale bars, $1 \mathrm{~cm}$. $\mathbf{f}$ The average tumor weight of each group is expressed as the mean \pm S.D. $\mathbf{g}$ The average inhibitory rate of tumor growth was calculated. The inhibitory rate of tumor growth $=\left(1\right.$ - tumor weight of AA005 group/tumor weight of control group) $\times 100 \%$. ${ }^{*} P<0.05$; ${ }^{* *} P<0.01$ vs. the vehicle control group

Plasmids and shRNAs

Plasmids for knockdown were constructed by inserting the corresponding shRNA sequences into the pGIPz plasmid (Dharmacon). The shRNA sequences are listed as follows: TAGCGGTCGCCGAAATGTT (shAIF\#1), CTGGTATCCGATCAGAGAG (shAIF\#2), TACAAATACATTTACAAGC (shMcl-1\#1), and TGTTAGCCATAATCCTCTT (shMcl-1\#2). Plasmids expressing Flag-tagged Mcl-1 were generated by inserting the corresponding coding sequence into a pBabe-Flag vector (Clontech, CA, USA). After co-transfection of lentiviral packaging plasmids into 293T cells, lentivirus-containing supernatants were harvested $48 \mathrm{~h}$ after transfection. SW620 or RKO cells were infected with the lentiviral supernatant and selected by puromycin.

Statistical analysis

All in vitro experiments were repeated at least three times with similar results. The results are expressed as the mean \pm S.D. The $P$-values for comparison between groups were obtained via Student's $t$-test. All statistical tests were two-sided, and $P$-value $<$ $0.05\left(^{*}\right)$ was considered to be statistically significant.

\section{RESULTS}

AA005 exhibits antitumor activity in xenografts of colon cancer SW620 cells

To examine the antitumor activity of AA005 in vivo, athymic nude mice bearing implanted xenografts of colon cancer cell line SW620 were treated with AA005 (Fig. 1a) or vehicle control. Treatment with AA005 resulted in a dramatic suppression of tumor growth 13 days following drug exposure (Fig. 1b). In contrast, no significant change in body weight was noted in a comparison of the vehicle control and AA005 regimen (Fig. 1c), indicating that no severe toxicity was observed. At the end of the growth period, the mean tumor volume was 3.7 times higher for the control group than the AA005-treated group (1178 vs. 318 $\mathrm{mm}^{3}, P=0.019$; Fig. $1 \mathrm{~b}, \mathrm{~d}$ and e), with a mean tumor weight that was three times higher for the control group than the AA005treated group ( 0.6 vs. $0.2 \mathrm{~g}, P=0.005$; Fig. $1 \mathrm{f})$. The average inhibitory rate of tumor growth was $67.5 \%$ (Fig. 1g). Thus treatment with AA005 produced obvious tumor growth inhibition effects without toxicity to the animals. 
a
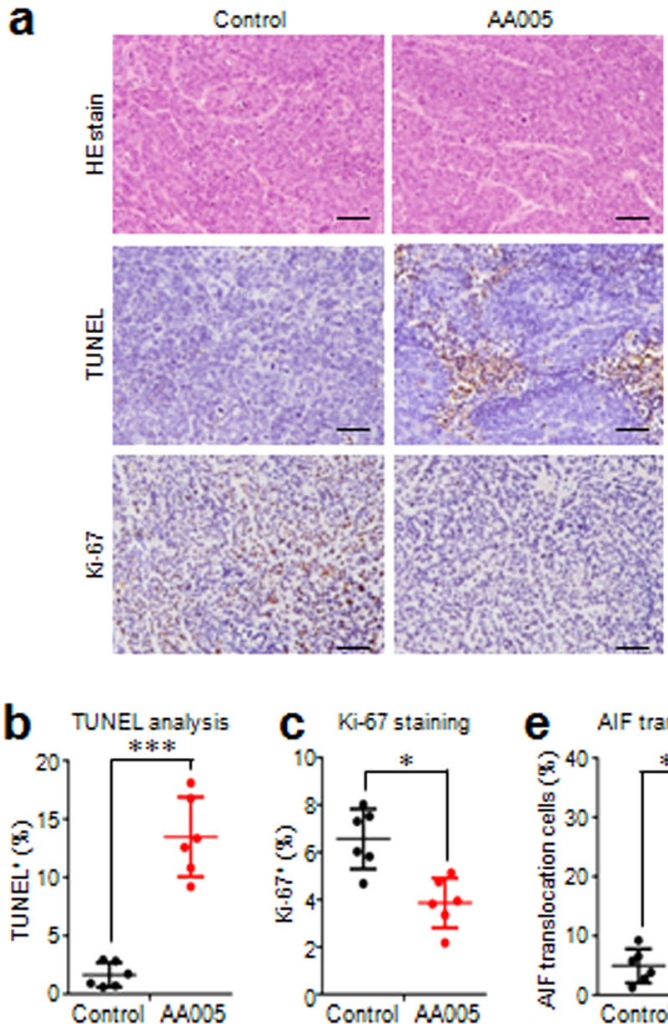

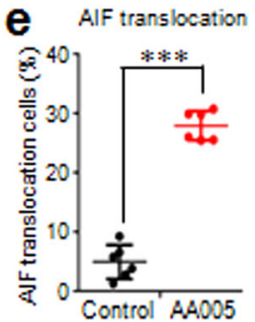

d
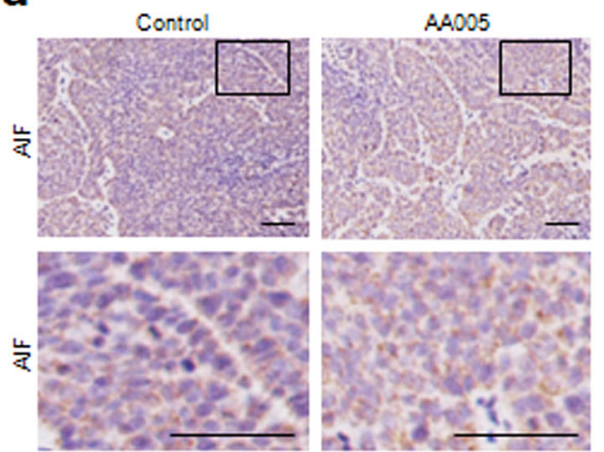

$\mathbf{f}$

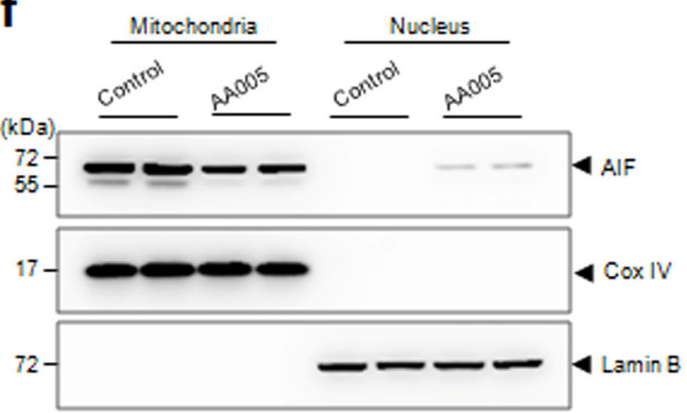

Fig. 2 Treatment with AA005 results in cell death and translocation of AIF in the xenograft animal model. a Tumors were obtained from mice 21 days after drug exposure. Tumors were fixed and stained with hematoxylin and eosin (H\&E) and assayed via TUNEL and Ki-67. Scale bars, $50 \mu \mathrm{m}$. b, c Image J software was used to quantify the TUNEL-positive cells (b) or Ki-67 positive cells (c) between the control and AA005treated group tumors. All bar graphs are plotted as the mean \pm S.D. $P$-values are calculated between linked groups. ${ }^{*} P<0.05 ;{ }^{* * *} P<0.001$. d Representative images of IHC staining of AIF in colon xenografts derived from vehicle- or AA005-treated SW620 cells. Lower panels show an enlarged picture of the boxed area. Scale bars, $50 \mu \mathrm{m}$. e Image J software was used to quantify the AIF translocation cells between the control and AA005-treated group tumors. $f$ Analysis of AlF translocation by subcellular fractionation. Western blots for the indicated proteins were derived from colon xenograft tumors with or without AA005 treatment. COX IV and Lamin B were used as mitochondrial and nuclear marker proteins, respectively

Treatment with AA005 results in cell death and translocation of AIF in the xenografts

To validate the antitumor effect of AA005, we first determined the cell death in the tumor tissue of the colon cancer xenograft using TUNEL assay. The TUNEL-positive cells of the tumor sections were significantly increased in AA005-treated SW620 xenograft mice compared with the control group (Fig. 2a, b). In contrast, a weak reduction in cell proliferation was noted in the AA005-treated group compared with the vehicle control, as indicated by $\mathrm{Ki}-67$ staining (Fig. 2c), suggesting that AA005 inhibited tumor growth primarily through induction of cell death.

Our previous findings suggested that AA005 triggered caspase3-independent cell death mediated by AIF in vitro [7], and thus we aimed to explore the effect of AIF on AA005-administered mice. Notably, nuclear translocation of AIF in tumor sections of SW620 xenograft mice increased upon AA005 treatment, as shown by IHC staining (Fig. 2d, e). Moreover, the increased level of AIF was determined in the nucleus of tumor fractions derived from the nude mice treated with AA005 as observed in Western blots (Fig. 2f). Together, these results indicated that AIF potentially contributes to AA005-induced cell death in vivo.

Exposure of colon cancer cells to AA005 results in the downregulation of $\mathrm{Mcl}-1$

To elucidate the mechanisms of AA005-induced cell death, we administered AA005 to colon cancer cell line SW620, followed by cell viability analysis with trypan-blue exclusion assays. A dose-dependent study revealed that the percentages of dead cells were $22.62 \pm 2.89 \%, 53.89 \pm 1.79 \%, 66.73 \pm 2.40 \%$, and $75.00 \pm$ $1.33 \%$ when SW620 cells were treated for $48 \mathrm{~h}$ with $0.2,1,5$, and $25 \mu \mathrm{M}$ AA005, respectively (Fig. 3a). Time-course analysis including treatment with AA005 for 12,24 , and $48 \mathrm{~h}$ showed that the cell death-inducing activity of AA005 was also time-dependent (Fig. 3a). Furthermore, Annexin-V/PI double stain-based flow cytometry analysis indicated that although nearly $60 \%$ of cells had died at $48 \mathrm{~h}$ with $1 \mu \mathrm{M}$ AA005 treatment, no obvious Annexin$\mathrm{V}^{+} / \mathrm{PI}^{-}$cells were detected throughout this process (Fig. $3 \mathrm{~b}$ ), indicating that AA005-induced cell death does not represent classical apoptosis. TUNEL analysis [31] of the $1 \mu \mathrm{M}$ AA005 treatment group showed increased TUNEL-positive cells, indicating that AA005 induced DNA fragmentation (Fig. 3c). Subcellular fractionation assays also showed AIF translocation into the nucleus after treatment with AA005, which was consistent with the results in vivo (Fig. 3d). Thus AA005 promoted AIF nuclear translocation and triggered AIF-dependent cell death in vitro.

However, the intrinsic cell death signaling that triggers AIF translocation to cause AA005-induced cell death remains ambiguous. We sought to further clarify the molecular mechanisms of AA005 killing of cancer cells. Reportedly, anti-apoptotic Bcl-2 family proteins play an important role in the regulation of cell death by AIF [32]. The effects of AA005 on the expression of Bcl-2 family proteins were examined in SW620 cells. Exposure of cells to $1 \mu \mathrm{M}$ AA005 for the indicated time resulted in a significant timedependent decrease in levels of $\mathrm{Mcl}-1$. Furthermore, translocation 

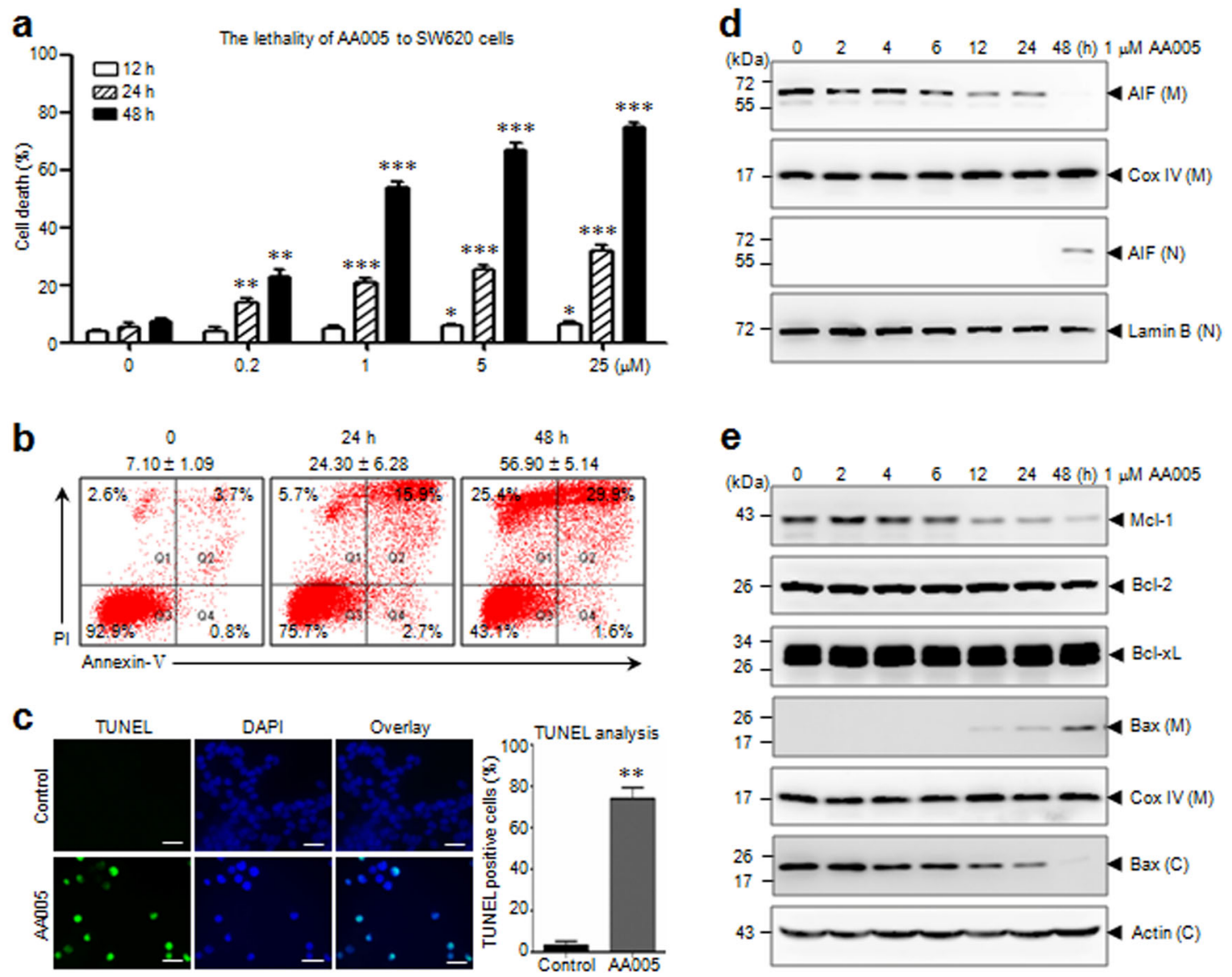

Fig. 3 AA005 induces AIF-dependent parthanatos in SW620 cells. a SW620 cells were treated with AA005 at the indicated concentrations. Cell death was measured by trypan-blue exclusion assay. ${ }^{*} P<0.05$; ${ }^{* *} P<0.01 ;{ }^{* *} P<0.001$, vs. vehicle control group. b SW620 cells were treated with $1 \mu \mathrm{M}$ AA005 for 24 or $48 \mathrm{~h}$. Cells were stained with Annexin-V/PI, and the percentage of dead cells was determined using flow cytometry. c TUNEL analysis of SW620 cells treated with or without $1 \mu \mathrm{M}$ AA005. Images were viewed using an Olympus BX-51 fluorescence microscope. Scale bars: $20 \mu \mathrm{m}$. ${ }^{* * P}<0.01$. d, e After treatment with AA005 for the indicated time, total cellular extracts and subcellular fractionations were subjected to Western blot analysis using antibodies against AIF, Mcl-1, Bcl-2, Bcl-xL, and Bax. COX IV (mitochondrial fractions; M), Lamin B (nuclear extracts; N), and actin (cytosolic fractions; C) were used to ensure equivalent loading

of Bax from the cytosol to mitochondria was noted in cells treated with AA005. In contrast, exposure of cells to AA005 did not discernibly modify the expression of other Bcl-2 family proteins, including $\mathrm{BCl}-2$ and $\mathrm{BCl}-\mathrm{xL}$ (Fig. 3e).

To determine whether the AA005-mediated lethality observed in SW620 cells also occurs in other colon cancer cell lines, parallel studies were performed in RKO cells. Consistent with the findings in SW620 cells, the same AA005 concentrations and exposure intervals resulted in a pronounced increase in cell death (Fig. 4a) and non-canonical apoptotic cell death (Fig. 4b). Similarly, AA005 induced an increase in TUNEL-positive RKO cells (Fig. 4c). These events were also accompanied by nuclear AIF accumulation (Fig. 4d), downregulation of Mcl-1 and translocation of Bax (Fig. 4e). These findings indicated that AA005induced cell death is in association with $\mathrm{Mcl}-1$ downregulation in colon cancer cells.

Downregulation of $\mathrm{Mcl}-1$ by AA005 proceeds through inhibition of transcription and translation

To elucidate the mechanism underlying $\mathrm{Mcl}-1$ downregulation by AA005, Mcl-1 mRNA expression in AA005-treated cells was quantified using real-time RT-PCR. Notably, treatment of SW620 cells with $1 \mu \mathrm{M}$ AA005 resulted in a significant decrease in the expression levels of Mcl-1 mRNA after $4 \mathrm{~h}$ of drug exposure (Fig. 5a). Similarly, the expression levels of Mcl-1 mRNA were reduced after AA005 treatment for $6 \mathrm{~h}$ in RKO cells
(Supplementary Figure S1). Such findings suggested that AA005 downregulated $\mathrm{Mcl}-1$ protein through inhibition of transcription.

To determine whether the downregulation of $\mathrm{Mcl}-1$ mediated by AA005 occurs through the proteasome pathway, SW620 cells were pretreated with or without AA005 for $4 \mathrm{~h}$, followed by treatment with proteasome inhibitor MG132 for the indicated time (Fig. 5b), which demonstrated that treatment with MG132 alone did not affect the protein level of $\mathrm{Mcl}-1$ and that the combination of AA005 and MG132 did not block the downregulation of $\mathrm{Mcl}-1$ mediated by AA005. These findings suggest that downregulation of $\mathrm{Mcl}-1$ mediated by AA005 does not occur through the proteasome pathway.

We also investigated the effect of protein synthesis inhibitor cycloheximide (CHX) on the downregulation of $\mathrm{Mcl}-1$ mediated by AA005. The protein level of $\mathrm{Mcl}-1$ was significantly decreased after $\mathrm{CHX}$ treatment for $4 \mathrm{~h}$, but no obvious changes were noted at $2 \mathrm{~h}$. However, the combination treatment of AA005 and CHX showed a significant decrease of $\mathrm{Mcl}-1$ at $2 \mathrm{~h}$, indicating that AA005 possibly reduces the half-life of $\mathrm{Mcl}-1$ by suppressing the synthesis of this protein (Fig. 5c).

Mcl-1 potentially contributes to AA005-induced AIF-dependent cell death

To address whether $\mathrm{Mcl}-1$ regulates AIF translocation induced by AA005, two pairs of shRNAs (shAIF\#1 and shAIF\#2) targeted 

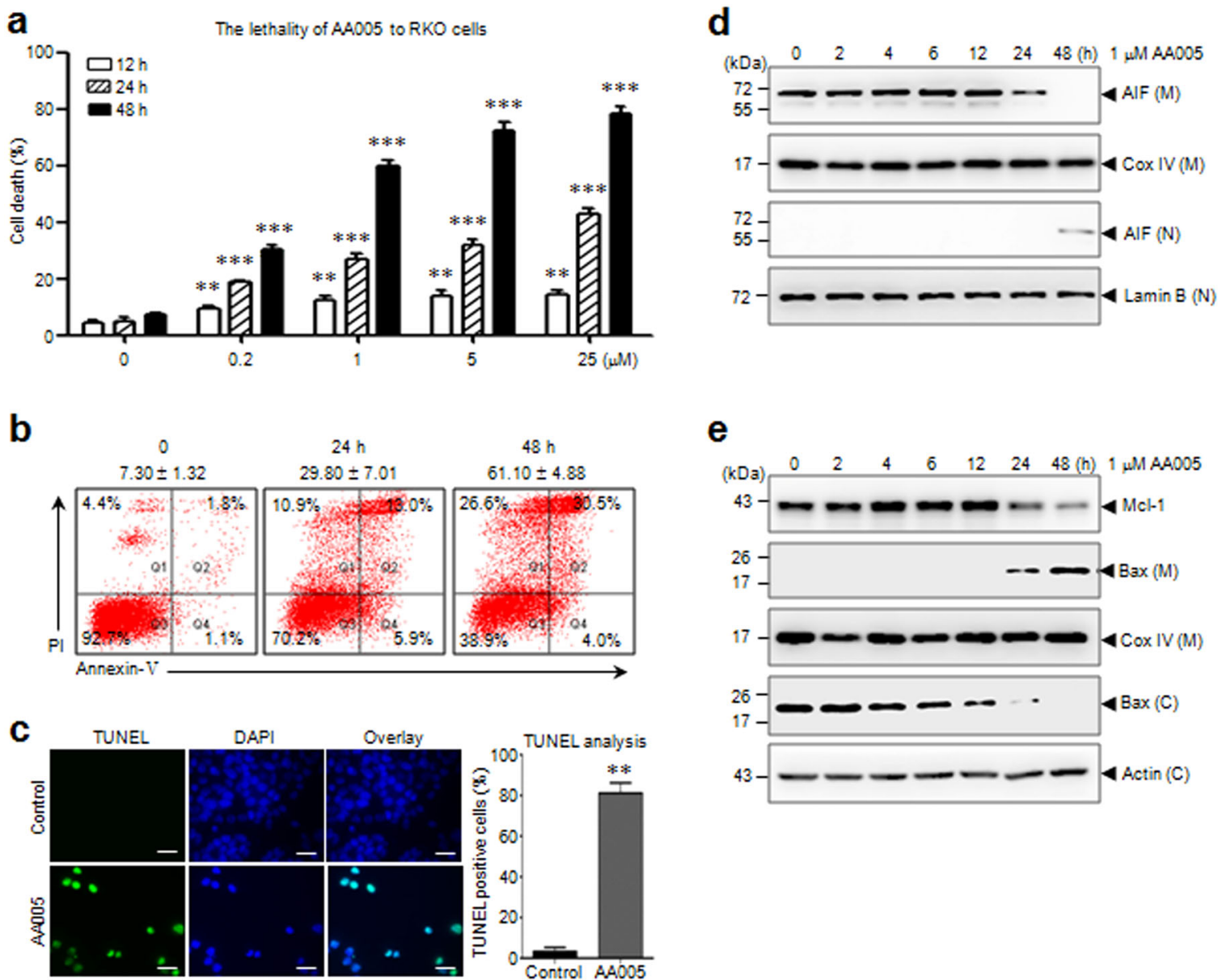

Fig. 4 AA005 induces AIF-dependent parthanatos in RKO cells. a RKO cells were treated with AA005 at the indicated concentrations for 12 , 24 , or $48 \mathrm{~h}$. Cell death was measured by trypan-blue exclusion assay. ${ }^{* *} P<0.01 ;{ }^{* *} P<0.001$ vs. the vehicle control group. b RKO cells were treated with $1 \mu \mathrm{M}$ AA005. Cells were stained with Annexin-V/PI, and the percentage of dead cells was determined using flow cytometry. c TUNEL analysis of RKO cells treated with or without $1 \mu \mathrm{M}$ AA005. Images were viewed using an Olympus BX-51 fluorescence microscope. Scale bars: $20 \mu \mathrm{m}$. ${ }^{*} P<0.01$. d, e After treatment with AA005 for the indicated time, total cellular extracts and subcellular fractionations were prepared and subjected to Western blot analysis using antibodies against AIF, Mcl-1 and Bax. COX IV (mitochondrial fractions; M), Lamin B (nuclear extracts; N), and actin (cytosolic fractions; C) were used to ensure equivalent loading

specifically against AIF were used to knockdown AIF expression together with the non-specific scramble shRNA (shNC) as a negative control. shRNA but not shNC significantly silenced AIF expression (Fig. 6a), whereas AIF knockdown failed to affect the downregulation of Mcl-1 evoked by AA005 (Fig. 6a). In accordance, SW620 cells were stably transfected with a lentivirus harboring shNC or shRNA (shMcl-1\#1) against $\mathrm{Mcl}-1$. The absence of $\mathrm{Mcl}-1$ expression was confirmed by Western blot analysis (Fig. 6b). Notably, knockdown of Mcl-1 in SW620 cells accelerated AIF translocation and a slight increase in Bax translocation to the mitochondria after AA005 treatment compared with control cells (Fig. 6c, d). These observations implied that Mcl-1 downregulation was required for AIF translocation from the mitochondria to the nucleus and that $\mathrm{Mcl}-1$ was potentially a crucial upstream regulator of AIF in AA005-induced cell death.

Diminished expression of $\mathrm{Mcl}-1$ by RNA interference enhances AA005-mediated lethality

To further confirm the functional role of $\mathrm{Mcl}-1$ in AA005-mediated lethality in colon cancer cells, shRNAs targeted specifically against $\mathrm{Mcl}-1$ were used to knockdown Mcl-1 expression together with shNC as a negative control in SW620 and RKO cells. shRNA but not shNC significantly silenced Mcl-1 expression (Fig. 7a). Knockdown of $\mathrm{Mcl}-1$ in SW620 cells increased cell death by $~ 30 \%$ at each dose of AA005 compared with control cells (Fig. 7b), and similar findings were observed in RKO cells (Fig. 7c). These data indicated that Mcl-1 had a critical role in AA005-mediated cell death.

Ectopic expression of $\mathrm{Mcl}-1$ attenuates AA005-mediated lethality To determine whether downregulation of $\mathrm{Mcl}-1$ has a functional role in AA005-induced cell death, SW620 and RKO cells that stably overexpressed $\mathrm{Mcl}-1$ were selected (Fig. 7d). Overexpression of Mcl-1 in the two cell lines displayed more than two-fold increases in $\mathrm{Mcl}-1$ protein levels compared with the empty vector control (EV) (Fig. 7d). Significantly, enforced expression of Mcl-1 attenuated AA005-mediated cell death both in SW620 (Fig. 7e) and RKO cells (Fig. 7f). Taken together, these findings indicated that $\mathrm{Mcl}-1$ downregulation has a significant functional role in AA005mediated lethality.

Mcl-1 downregulation mediates the in vivo antitumor effects of AA005

Given that $\mathrm{Mcl}-1$ downregulation had a significant functional role in AA005-mediated lethality in vitro, whether Mcl-1 downregulation also affected tumor growth in vivo was further investigated. To this end, we subcutaneously injected shNC or shMcl-1\#1infected SW620 cells into the flanks of nude mice and treated them with AA005 or vehicle control. Consistent with the antitumor effects in colon cancer cells (Fig. 7b, c), the tumor growth inhibitory effect of AA005 was significantly enhanced in the silent 

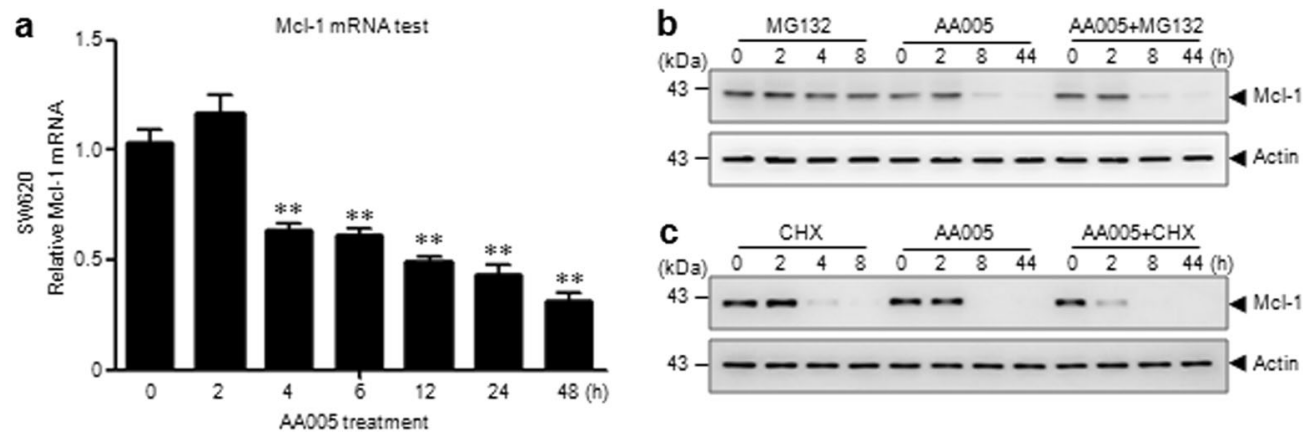

Fig. 5 AA005 induces Mcl-1 downregulation through inhibition of transcription and translation in SW620 cells. a SW620 cells were treated with $1 \mu \mathrm{M}$ AA005 at the designated intervals, after which total RNA were isolated, and Mcl-1 mRNA were quantified using real-time reverse transcription-polymerase chain reaction (RT-PCR). ${ }^{* *} P<0.01$ vs. control group. b, c SW620 cells were pretreated with or without AA005 (1 $\mu$ M) for $4 \mathrm{~h}$ followed by MG132 $(1 \mu \mathrm{M})$ or $\mathrm{CHX}(2 \mu \mathrm{M})$ treatment for the indicated time. Total cellular extracts were prepared and subjected to Western blot assay using antibodies against $\mathrm{Mcl}-1$ and actin
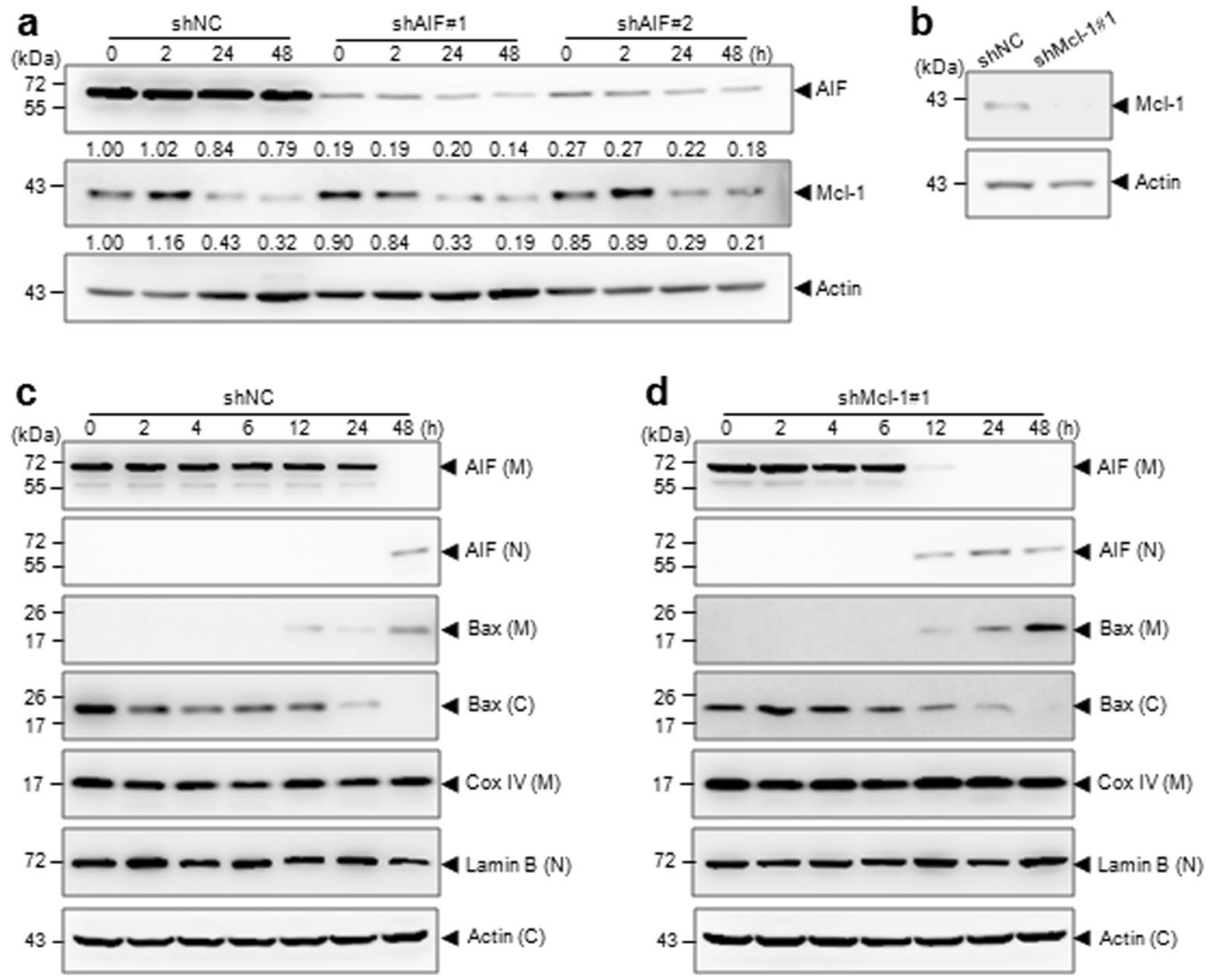

Fig. $6 \mathrm{Mcl}-1$ is an upstream regulator of AIF in AA005-induced cell death. a SW620 cells were stably transfected with a lentivirus-containing shRNA specific for scrambled negative control (shNC) or AIF (shAIF\#1 and shAIF\#2). After treatment with AA005 for the indicated time, total cellular extracts were subjected to Western blot assay using antibodies against AIF and Mcl-1 and standardized to actin. b-d SW620 cells were stably transfected with lentivirus-containing shNC or Mcl-1 (shMcl-1\#1), and the absence of Mcl-1 expression was confirmed by Western blot analysis standardized to actin (b), shNC (c), and shMcl-1\#1 (d). Cells were treated with $1 \mu \mathrm{M}$ AA005 for the indicated time, and subcellular fractionations were subjected to Western blot assay using antibodies against AIF and Bax. COX IV (mitochondrial fractions; M), Lamin B (nuclear extracts; N), and actin (cytosolic fractions; $\mathrm{C}$ ) were used to ensure equivalent loading

Mcl-1 expression group compared with the control group (Fig. 8a). No significant change in body weight was noted compared with the control group and the shMcl-1 group with or without AA005 treatment (Fig. 8b), indicating that no severe toxicity to the animals occurred.

At the end of the growth period, the mean tumor volume was 5.4 times higher for the vehicle-treated shNC group than the AA005-treated shMcl-1 group (1446 vs. $267 \mathrm{~mm}^{3}, P=0.0001$ ) and
2.5 times higher for the AA005-treated shNC group than the AA005-treated shMcl-1 group (663 vs. $267 \mathrm{~mm}^{3}, P=0.0026$ ) (Fig. 8a, c). The mean tumor weight was 4.2 times higher for the vehicle-treated shNC group than the AA005-treated shMcl-1 group ( 0.65 vs. $0.15 \mathrm{~g}, P=0.0002)$ and three times higher for the AA005-treated shNC group than the AA005-treated shMcl-1 group ( 0.45 vs. $0.15 \mathrm{~g}, P=0.0012$ ) (Fig. $8 \mathrm{~d}, \mathrm{e})$. Compared with the control tumors, silent $\mathrm{Mcl}-1$ expression tumors were significantly more 
a
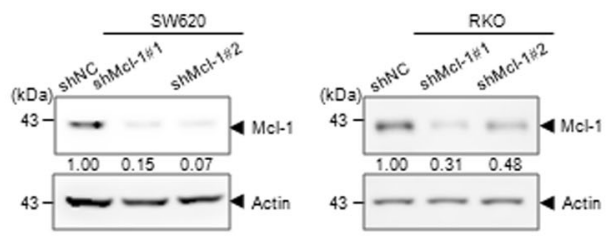

b

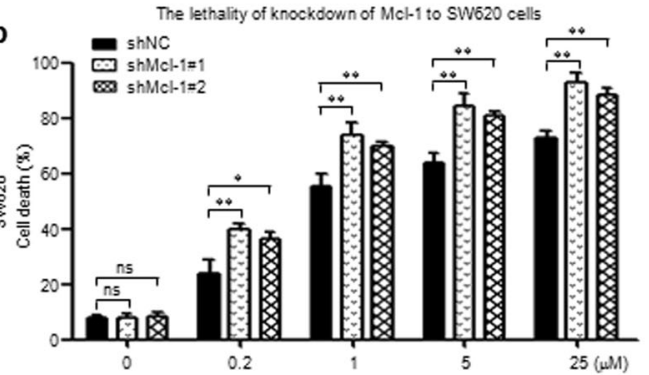

C

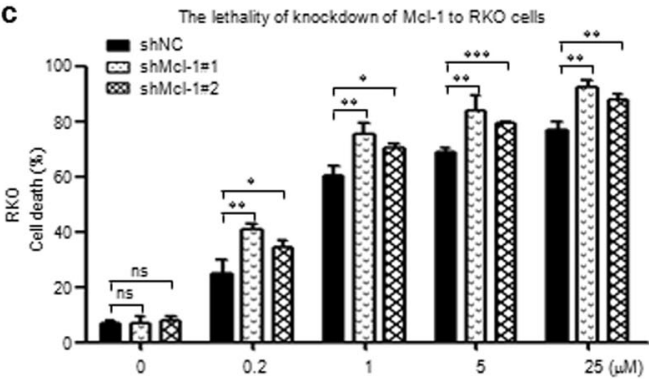

d
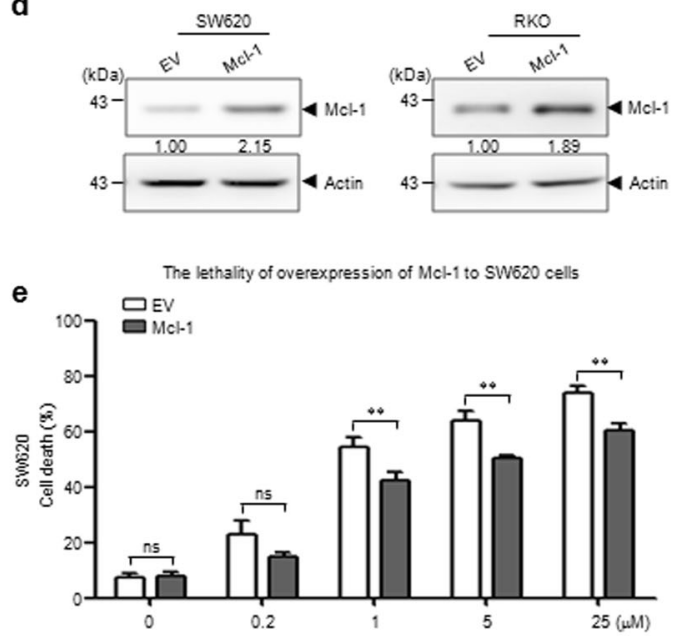

f

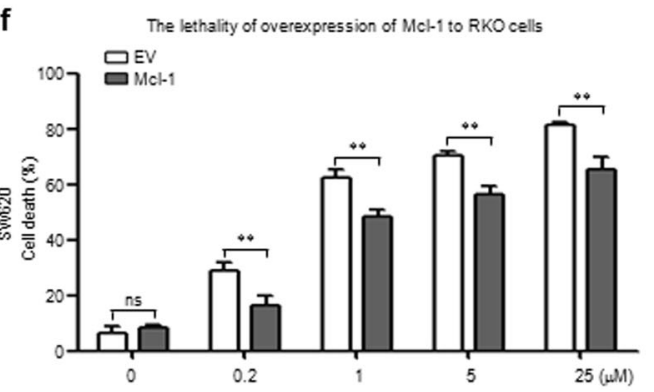

Fig. 7 Diminished expression of $\mathrm{Mcl}-1$ by RNA interference enhances AA005-mediated lethality, whereas ectopic expression of Mcl-1 attenuates AA005-mediated lethality in colon cancer cells. a-c SW620 cells and RKO cells were stably transfected with lentivirus-containing shRNAs specific for scrambled negative control (shNC) or Mcl-1 (shMcl-1\#1 and shMcl-1\#2), respectively, and the absence of Mcl-1 expression was confirmed by Western blot analysis standardized to actin (a). shNC or shMcl-1 of SW620 cells (b) or RKO cells (c) were treated with AA005 at the indicated concentrations for $48 \mathrm{~h}$. Cell death was measured by trypan-blue exclusion assay. d-f SW620 cells and RKO cells were stably transfected with lentivirus containing an empty vector or $\mathrm{Mcl}-1$ overexpressing vector (Mcl-1), respectively, and subjected to Western blot assay using an antibody against Mcl-1 (d). Mcl-1 and EV cells of SW620 (e) or RKO (f) were treated with AA005 for $48 \mathrm{~h}$. Cell death was measured by trypan-blue exclusion assay. ${ }^{*} P<0.05 ;{ }^{* *} P<0.01 ;{ }^{* *} P<0.001$ vs. the control group

sensitive to AA005. Consistent with the in vitro findings, silent $\mathrm{Mcl}-$ 1 expression substantially enhanced AA005-induced cell death, as indicated by TUNEL staining (Fig. 8f). Furthermore, Mcl-1 expression in tumor sections of SW620 xenograft mice decreased upon AA005 treatment, as measured by immunohistochemical staining (Fig. 8f) and Western blots (Fig. 8g), which was consistent with the former results (Fig. 3e). These results demonstrated a pivotal role of $\mathrm{Mcl}-1$ downregulation in mediating the in vivo antitumor effects of AA005.

Mcl-1 downregulation is upstream of RIP-1 activation

Our previous findings suggested that AA005 could trigger AIFdependent cell death, which is mediated through RIP-1 [7], and therefore, we aimed to explore the relationship between $\mathrm{Mcl}-1$ downregulation and activation of RIP-1. Inhibition of RIP-1 by Necrostatin-1 (Nec-1) or RIP-1 knockdown failed to affect the downregulation of $\mathrm{Mcl}-1$ after AA005 treatment (Fig. 9a, b). However, Mcl-1 knockdown accelerated upregulation of RIP-1 induced by AA005 (Fig. 9c), and enforced expression of $\mathrm{Mcl}-1$ attenuated upregulation of RIP-1 induced by AA005 (Fig. 9d). Furthermore, the RIP-1 expression of xenograft tumor tissues in the AA005-treated shMcl-1 group was higher than that in the control group, as measured by Western blots (Fig. 9e), which was consistent with the former in vitro results. These results implied that $\mathrm{Mcl}-1$ potentially acts as a crucial upstream regulator and mediates upregulation of RIP-1 and AIF translocation in
AA005-induced cell death. Taken together, we present an illustration of the potential mechanisms of AA005 action in colon cancer cells (Fig. 9f).

\section{DISCUSSION}

Annonaceous acetogenins represent a series of C-35/C-37 natural products with hydroxylated THF and $\gamma$-lactone ring structures. Many members of this family display cytotoxic activity by perturbation of the terminal electron transfer step in complex I of mitochondria. AA005 is a mimetic of annonaceous acetogenin in which both of the THF rings are replaced by an ethylene glycol ether unit. AA005 retains the essential functionalities of the natural acetogenins and shows more powerful biological activity [3, 7, 33-36]. However, the in vivo antitumor effects and the detailed mechanisms of AA005 action remain ambiguous. In our previous work, we found that AA005 could induce cell death in colorectal adenocarcinoma cells, as characterized by lack of caspase-3 activation or apoptotic body formation, sensitivity to poly(ADP-ribose) polymerase inhibitor Olaparib (AZD2281) but not pan-caspase inhibitor Z-VAD.fmk, and dependence on AIF, similar to that of the DNA-alkylating agent $N$-methyl- $N$-nitro- $N$-nitrosoguanidine (MNNG)-treated cell death [7]. This caspase-independent type of apoptosis is known as parthanatos [37]. In this study, we report that AA005 has favorable antitumor activity in vivo as indicated by suppression of tumor growth through induction of 

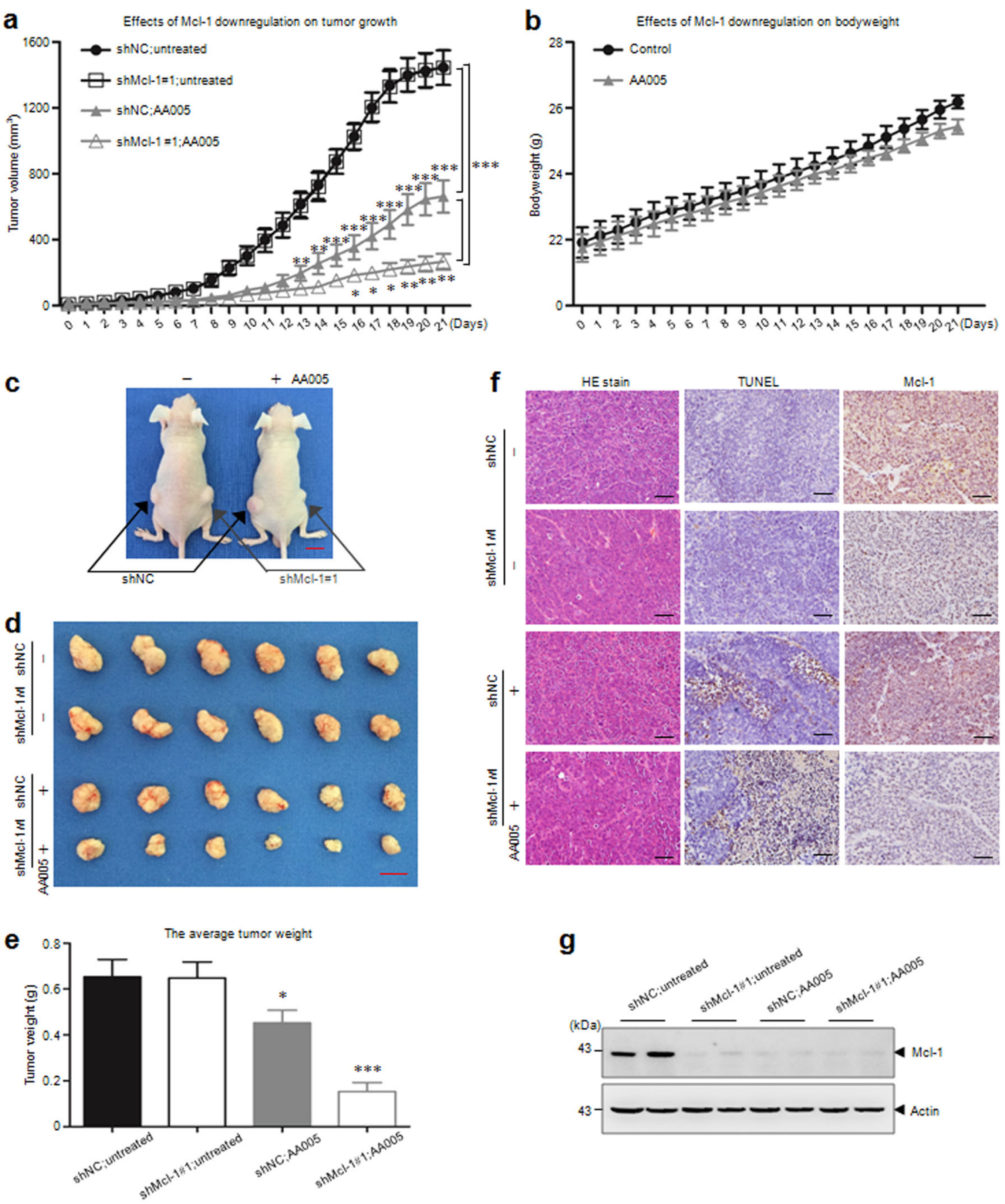

Fig. $8 \mathrm{Mcl}-1$ downregulation mediates the in vivo antitumor effects of AA005. a 5-week-old nude mice were inoculated subcutaneously with shNC or shMcl-1\#1-infected SW620 cells $\left(1 \times 10^{6} / 0.2 \mathrm{~mL}\right.$ per mouse). After 1 week, mice were treated with $5 \mathrm{mg} / \mathrm{kg}$ AA005 daily (intraperitoneally) or with the vehicle control for 21 consecutive days. The tumor volume was calculated ( 6 mice per group). ${ }^{*} P<0.05$; ${ }^{*} P<0.01 ;{ }^{* * *} P<0.001$ vs. the vehicle control group. $\mathbf{b}$ Body weight of mice during the 21 days of drug treatment. $\mathbf{c}$ Representative image of tumors in nude mice at the end of the experiment. Scale bars, $1 \mathrm{~cm}$. $\mathbf{d}$ Tumors of each group when nude mice were killed (6 mice per group). Scale bars, $1 \mathrm{~cm}$. e The average tumor weight of each group is expressed as the mean \pm S.D. ( 6 mice per group). $f$ Tumors were obtained from mice, fixed, and stained with hematoxylin and eosin (H\&E), assayed via TUNEL, and the levels of MCL-1 were determined using immunohistochemistry. Scale bars, $50 \mu \mathrm{m}$. g Western blots for the expression levels of MCL-1 in each tumor group

AIF-dependent cell death. The results also strongly support our recent study [7].

Directed induction of cell death could offer therapeutic benefits for cancer treatment. Such treatments primarily target the caspase pathways to induce apoptosis [26, 38-40]. However, caspase activation might be dispensable for certain types of apoptosis, and increasing attention has been drawn to key molecules involved in non-apoptotic cell death or caspase-independent apoptosis [41-48]. The mitochondrial protein AIF is a new therapeutic target involved in most of the caspase-independent apoptosis systems, including programmed necrosis [38, 49-52]. As a core executor in caspaseindependent cell death, AIF has been intensively studied [41], but many study results are highly controversial. We suggest that AA005 is an effective chemical probe for examining the role of AIF. 
$\mathbf{a}$

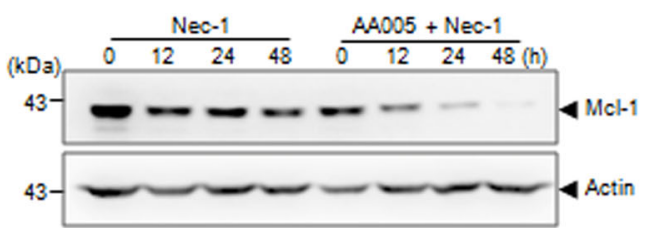

b

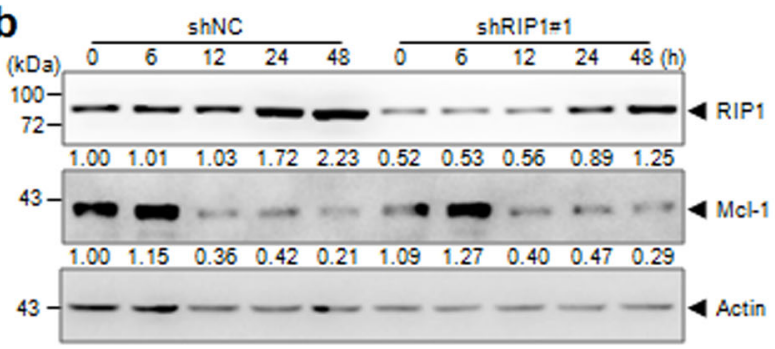

c
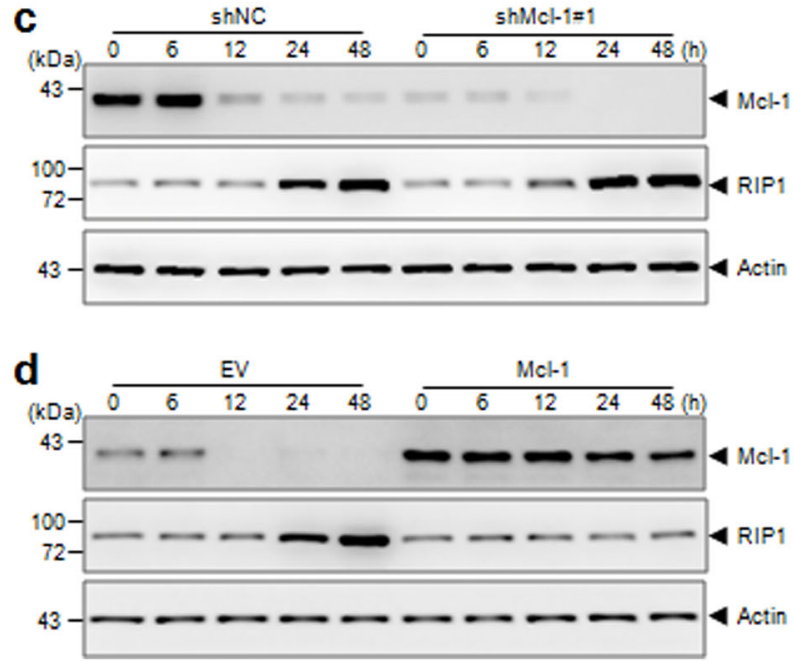
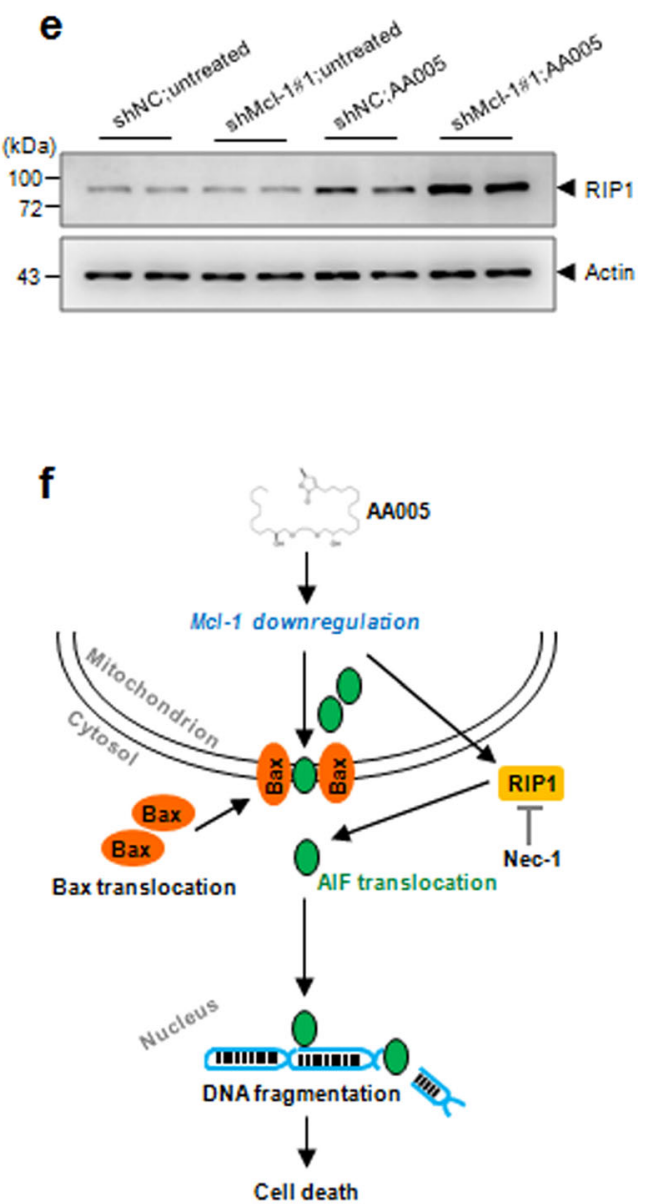

Fig. $9 \mathrm{Mcl}-1$ downregulation is upstream of RIP-1 activation and a sketch of mechanisms of AA005 action in colon cancer cells. a Immunoblotting analysis of the expressional level of Mcl-1 with $1 \mu \mathrm{M}$ AA005 treatment for the indicated time after pretreatment with or without RIP-1 inhibitor Necrostatin-1 (Nec-1; $100 \mu \mathrm{M})$. b SW620 cells were stably transfected with lentivirus-containing small interfering RNA (siRNA) specific for the control (siControl) or RIP-1 (siRIP-1). After AA005 treatment, expression of the indicated proteins was confirmed by Western blot analysis. c SW620 cells were stably transfected with lentivirus-containing siControl or siRNA specific for Mcl-1 (siMcl-1). Cells were treated with $1 \mu \mathrm{M}$ AA005 for the indicated time. Mcl-1 and RIP-1 were examined via Western blots standardized to actin. d SW620 cells were stably transfected with lentivirus containing the empty vector (EV) or Mcl-1 overexpressing vector (Mcl-1). After AA005 treatment, expression of the indicated proteins was confirmed by Western blots. e Western blots for the expression levels of RIP-1 in each group tumor standardized to actin. $\mathbf{f}$ A sketch of the mechanisms of AA005 action in colon cancer cells

Furthermore, AA005 might represent the basis of a novel treatment for cancers that are resistant to classical apoptotic reagents.

Notably, our results demonstrate for the first time that downregulation of $\mathrm{Mcl}-1$ has an important role in AA005-mediated lethality. One of the hallmarks of cancer is its resistance to apoptosis, which maintains survival of cells en route to oncogenic transformation [53]. Overexpression or amplification of $M \mathrm{Cl}-1$ is one of the most frequent alterations in human cancers [54]. Defective Mcl-1 degradation allows tumor cells to evade the fate of death and underlies development of therapeutic resistance. The development of anticancer agents that diminish $\mathrm{Mcl}-1$ protein levels has been the focus of intense interest $[55,56]$. Indeed, a number of studies have documented $\mathrm{Mcl}-1$ downregulation during apoptosis by a variety of agents, including ultraviolet (UV) [57], kinase inhibitor BAY 43-9006 [58], and growth factor withdrawal [59], among others. Our work might offer new clues for cancer therapy and treatment that combines AA005 with other agents targeting Mcl-1.

It has been shown that several cyclin-dependent kinase inhibitors (including SU9516, flavopiridol, and seliciclib) downregulate Mcl-1 expression in cancer cells through inhibition of RNA polymerase
(Pol) II, leading to transcriptional repression [60-62]. Furthermore, SU9516-induced inhibition of Mcl-1 transcription and phosphorylation of RNA Pol II is reactive oxygen species (ROS) dependent. Our previous study showed that AA005 treatment resulted in a marked increase in ROS production at the early stage, which was diminished together with cell death by the free radical scavenger $\mathrm{N}$ acetylcysteine [7]. On the basis of these data, we hypothesize that AA005 kills colorectal adenocarcinoma cells sequentially through inhibition of phosphorylation of the carboxyl-terminal domain of RNA Pol II in association with oxidative damage and downregulation of $\mathrm{Mcl}-1$ at the transcriptional level, culminating in mitochondrial injury and cell death. In addition, it is highly useful to reveal which protein is directly regulated by AA005 during the cell death through chemical proteomics, small molecule/protein crystal structure analysis and/or bioinformatics.

Cellular changes leading to inhibition of programmed cell death have an essential role in tumor development. Moreover, parthanatos represents AIF-induced DNA damage-related cell death. During this process, AIF is released from the mitochondria by a mechanism implicating MOMP [63], ROS production [64], or 
RIP-1/TRAF2-mediated Jun N-terminal protein kinase 1 activation [65]. It appears that $\mathrm{Bcl}-2$ family members are crucial to inducing MOMP and the subsequent release of apoptogenic molecules, thus leading to cell death. Bak resides on the outer mitochondrial membrane in healthy cells, where it has been reported as bound to $\mathrm{Mcl}-1$ [66] and Bcl-xL. With certain cytotoxic stimuli (such as AA005) induction, $\mathrm{Mcl}-1$ is degraded or downregulated, and the $\mathrm{Mcl}-1-\mathrm{Bak}$ interactions are disrupted by $\mathrm{BH} 3-$ only proteins such as NOXA, BIM, or BIK [67], which frees Bak. At the same time, Bax translocates from the cytosol to the mitochondria. Bax and Bak form pores in the membranes and facilitate the release of AIF from the mitochondrial intermembrane space to the cytosol. Once AIF translocates to the nucleus, it generates DNA breaks, chromatin condensation and the irreversible cell death of parthanatos (Fig. 9f). However, little is known of the upstream mechanisms that regulate AIF release from mitochondria. Previous reports have shown that calpain controls mitochondrial AIF release during MNNG-induced death [68]. Our data suggest that this process requires the cooperative upstream action of $\mathrm{Mcl}-1$ and $\mathrm{Bax} . \mathrm{Mcl}-1$ liberates Bak, yielding MOMP, and Bax facilitates the MOMP necessary for AIF release. Consequently, knockdown of $\mathrm{Mcl}-1$ accelerated AIF translocation, increased Bax translocation to mitochondria, and enhanced AA005-mediated lethality (Fig. 6d).

AIF-mediated and PARP-1-dependent parthanatos is caspaseindependent and lacks many morphological features of classic apoptosis [69]. However, unlike "accidental" necrosis, it has recently been reported as regulated necrosis [70]. RIP-1 is known as a major mediator in regulation of necrotic cell death [71]. Consistent with this view, data from our study suggest that caspase-independent cell death induced by AA005 also requires the function of RIP-1. In this work, we reveal that Mcl-1 and RIP-1 are upstream of AIF in AA005-induced parthanatos because AA005-induced nuclear AIF accumulation was attenuated in $\mathrm{Mcl}^{-1}{ }^{-1-}$ and RIP-1 inhibitor $\mathrm{Nec}-1-$ treated SW620 cells. Furthermore, Mcl-1 is upstream of RIP-1 because it influences RIP-1 activity. Our previous work found that AA005 treatment increased the intracellular concentrations of ROS. In fact, it has been reported that RIP-1 could modulate oxidative stress in AlF-dependent cell death. Therefore, we speculate that AA005 might disrupt mitochondrial function by downregulation of Mcl-1, thus triggering ROS, RIP-1, and the AIF-dependent pathway. This work offers a new clue to the action of AA005.

The mitochondria manage energy generation via citric acid cycle and also play a key role in apoptosis regulation through release of cytochrome $c$. Although much debate has focused on whether mitochondria contain defects in the oxidative phosphorylation pathway, they could offer a potential target for cancer therapy [72]. Mitochondria complex I has been shown to be targeted by annonaceous acetogenin. On the basis of our findings in colon cancer cells, we propose a model in which AA005 induces downregulation of Mcl-1 as an early event. Bax is translocated to the mitochondria and RIP-1 is upregulated, leading to the release of the apoptogenic molecule AIF into the cytosol, followed by its translocation to the nucleus, where it contributes to large-scale DNA fragmentation and irreversible cell death (Fig. 9f). However, why mitochondria in cancer cells are more prone to targeting by AA005 remains an open question.

In summary, these findings demonstrate that AA005 exhibits effective antitumor activity in vitro and in vivo by induction of cell death, which occurs in association with downregulation of $\mathrm{Mcl}-1$ and the AIF-dependent signaling pathway. This study strongly suggests that AA005 is a potential new agent for the treatment of colon cancer and deserves further preclinical and clinical studies.

\section{ACKNOWLEDGEMENTS}

This work was financially supported by the Fundamental Research Funds for Minhang Hospital (Grant No. 2016MHJC01), Shanghai Sailing Program (Grant No. 17YF1416700). This work is supported in part by grants from National Natural
Science Foundation of China (81472758, 31170783, U1302225, 21532002) and Shanghai (E09013, SKLGE-1510).

\section{AUTHOR CONTRIBUTIONS}

$\mathrm{BH}$ and $\mathrm{L}-\mathrm{sW}$ conceived and designed the experiments; $\mathrm{BH}, \mathrm{Y}-\mathrm{xC}$ and $\mathrm{Z}-\mathrm{mL}$ performed the experiments; $\mathrm{BH}, \mathrm{Z}-\mathrm{jY}$ and L-sW analyzed the data; Z-xW, Y-qM, H-IC, and Z-jY contributed reagents, materials, or analytical tools; $\mathrm{BH}$ and $\mathrm{L}-\mathrm{sW}$ wrote the paper.

\section{ADDITIONAL INFORMATION}

The online version of this article (https://doi.org/10.1038/s41401-018-0025-7) contains supplementary material, which is available to authorized users.

Competing interests: The authors declare no competing interests.

Publisher's note: Springer Nature remains neutral with regard to jurisdictional claims in published maps and institutional affiliations.

\section{REFERENCES}

1. Alali FQ, Liu XX, McLaughlin JL. Annonaceous acetogenins: recent progress. J Nat Prod. 1999;62:504-40.

2. Chang FR, Wu YC. Novel cytotoxic annonaceous acetogenins from Annona muricata. J Nat Prod. 2001;64:925-31.

3. Zeng BB, Wu Y, Jiang $S, Y u$ Q, Yao ZJ, Liu ZH, et al. Studies on mimicry of naturally occurring annonaceous acetogenins: non-THF analogues leading to remarkable selective cytotoxicity against human tumor cells. Chemistry. 2003:9:282-90.

4. Liu HX, Huang GR, Zhang HM, Jiang S, Wu JR, Yao ZJ. A structure-activity guided strategy for fluorescent labeling of annonaceous acetogenin mimetics and their application in cell biology. Chembiochem. 2007;8:172-7.

5. Huang GR, Jiang S, Wu YL, Jin Y, Yao ZJ, Wu JR. Induction of cell death of gastric cancer cells by a modified compound of the annonaceous acetogenin family. Chembiochem. 2003;4:1216-21.

6. Jiang S, Li Y, Chen XG, Hu TS, Wu YL, Yao ZJ. Parallel fragment assembly strategy towards multiple-ether mimicry of anticancer annonaceous acetogenins. Angew Chem Int Ed Engl. 2004;43:329-34.

7. Han B, Wang TD, Shen SM, Yu Y, Mao C, Yao ZJ, et al. Annonaceous acetogenin mimic AA005 induces cancer cell death via apoptosis inducing factor through a caspase-3-independent mechanism. BMC Cancer. 2015;15:139.

8. Liu YQ, Cheng X, Guo LX, Mao C, Chen YJ, Liu HX, et al. Identification of an annonaceous acetogenin mimetic, AA005, as an AMPK activator and autophagy inducer in colon cancer cells. PLoS ONE. 2012;7:e47049.

9. Newmeyer DD, Ferguson-Miller S. Mitochondria: releasing power for life and unleashing the machineries of death. Cell. 2003;112:481-90.

10. Ekert PG, Vaux DL. The mitochondrial death squad: hardened killers or innocent bystanders? Curr Opin Cell Biol. 2005;17:626-30.

11. Green DR, Kroemer G. The pathophysiology of mitochondrial cell death. Science. 2004;305:626-9.

12. Arnoult D, Grodet A, Lee YJ, Estaquier J, Blackstone C. Release of OPA1 during apoptosis participates in the rapid and complete release of cytochrome $c$ and subsequent mitochondrial fragmentation. J Biol Chem. 2005;280:35742-50.

13. Adams JM, Cory S. The BCl-2 apoptotic switch in cancer development and therapy. Oncogene. 2007:26:1324-37.

14. Moldoveanu T, Follis AV, Kriwacki RW, Green DR. Many players in BCL-2 family affairs. Trends Biochem Sci. 2014;39:101-11.

15. Bhola PD, Letai A. Mitochondria-judges and executioners of cell death sentences. Mol Cell. 2016;61:695-704.

16. Thomas LW, Lam C, Edwards SW. Mcl-1; the molecular regulation of protein function. FEBS Lett. 2010;584:2981-9.

17. Perciavalle RM, Opferman JT. Delving deeper: MCL-1's contributions to normal and cancer biology. Trends Cell Biol. 2013;23:22-9.

18. Kaufmann SH, Karp JE, Svingen PA, Krajewski S, Burke PJ, Gore SD, et al. Elevated expression of the apoptotic regulator $\mathrm{Mcl}-1$ at the time of leukemic relapse. Blood. 1998;91:991-1000.

19. Hussain SR, Cheney CM, Johnson AJ, Lin TS, Grever MR, Caligiuri MA, et al. Mcl-1 is a relevant therapeutic target in acute and chronic lymphoid malignancies: downregulation enhances rituximab-mediated apoptosis and complementdependent cytotoxicity. Clin Cancer Res. 2007;13:2144-50.

20. Zhou P, Qian L, Bieszczad CK, Noelle R, Binder M, Levy NB, et al. Mcl-1 in transgenic mice promotes survival in a spectrum of hematopoietic cell types and immortalization in the myeloid lineage. Blood. 1998;92:3226-39. 
21. Moulding DA, Giles RV, Spiller DG, White MR, Tidd DM, Edwards SW. Apoptosis is rapidly triggered by antisense depletion of MCL-1 in differentiating U937 cells. Blood. 2000;96:1756-63.

22. Opferman JT, Iwasaki H, Ong CC, Suh H, Mizuno S, Akashi K, et al. Obligate role of anti-apoptotic MCL-1 in the survival of hematopoietic stem cells. Science. 2005;307:1101-4.

23. Opferman JT, Letai A, Beard C, Sorcinelli MD, Ong CC, Korsmeyer SJ. Development and maintenance of $B$ and $T$ lymphocytes requires antiapoptotic MCL-1. Nature. 2003;426:671-6.

24. Wang L, Du F, Wang X. TNF-alpha induces two distinct caspase-8 activation pathways. Cell. 2008;133:693-703.

25. Degterev A, Hitomi J, Germscheid M, Ch'en IL, Korkina O, Teng X, et al. Identification of RIP1 kinase as a specific cellular target of necrostatins. Nat Chem Biol. 2008;4:313-21.

26. Yu Y, Wang LS, Shen SM, Xia L, Zhang L, Zhu YS, et al. Subcellular proteome analysis of camptothecin analogue NSC606985-treated acute myeloid leukemic cells. J Proteome Res. 2007;6:3808-18.

27. Morand JP, Macri J, Adeli K. Proteomic profiling of hepatic endoplasmic reticulum-associated proteins in an animal model of insulin resistance and metabolic dyslipidemia. J Biol Chem. 2005;280:17626-33.

28. Klotz AV, Stegeman JJ, Walsh C. An alternative 7-ethoxyresorufin O-deethylase activity assay: a continuous visible spectrophotometric method for measurement of cytochrome P-450 monooxygenase activity. Anal Biochem. 1984;140:138-45.

29. Gao N, Budhraja A, Cheng S, Yao H, Zhang Z, Shi X. Induction of apoptosis in human leukemia cells by grape seed extract occurs via activation of c-Jun NH2terminal kinase. Clin Cancer Res. 2009;15:140-9.

30. Zhao KW, Li X, Zhao Q, Huang Y, Li D, Peng ZG, et al. Protein kinase C delta mediates retinoic acid and phorbol myristate acetate-induced phospholipid scramblase 1 gene expression: its role in leukemic cell differentiation. Blood. 2004;104:3731-8.

31. Yang ZY, Qu Y, Zhang Q, Wei M, Liu CX, Chen XH, et al. Knockdown of metallopanstimulin-1 inhibits NF-kappaB signaling at different levels: the role of apoptosis induction of gastric cancer cells. Int J Cancer. 2012;130:2761-70.

32. Youle RJ, Strasser A. The BCL-2 protein family: opposing activities that mediate cell death. Nat Rev Mol Cell Biol. 2008;9:47-59.

33. Xiao Q, Liu Y, Qiu Y, Zhou G, Mao C, Li Z, et al. Potent antitumor mimetics of annonaceous acetogenins embedded with an aromatic moiety in the left hydrocarbon chain part. J Med Chem. 2011;54:525-33.

34. Liu HX, Huang GR, Zhang HM, Wu JR, Yao ZJ. Annonaceous acetogenin mimics bearing a terminal lactam and their cytotoxicity against cancer cells. Bioorg Med Chem Lett. 2007;17:3426-30.

35. Xiao Q, Liu Y, Qiu Y, Yao Z, Zhou G, Yao ZJ, et al. Design, synthesis of symmetrical bivalent mimetics of annonaceous acetogenins and their cytotoxicities. Bioorg Med Chem Lett. 2011;21:3613-5.

36. Yao ZJ, Wu HP, Wu YL. Polyether mimics of naturally occurring cytotoxic annonaceous acetogenins. J Med Chem. 2000;43:2484-7.

37. Yu SW, Wang H, Poitras MF, Coombs C, Bowers WJ, Federoff HJ, et al. Mediation of poly(ADP-ribose) polymerase-1-dependent cell death by apoptosis-inducing factor. Science. 2002;297:259-63.

38. Kim R. Recent advances in understanding the cell death pathways activated by anticancer therapy. Cancer. 2005;103:1551-60.

39. Song MG, Gao SM, Du KM, Xu M, Yu Y, Zhou YH, et al. Nanomolar concentration of NSC606985, a camptothecin analog, induces leukemic-cell apoptosis through protein kinase $C$ delta-dependent mechanisms. Blood. 2005;105:3714-21.

40. Gao YH, Wu ZX, Xie LQ, Li CX, Mao YQ, Duan YT, et al. VHL deficiency augments anthracycline sensitivity of clear cell renal cell carcinomas by down-regulating ALDH2. Nat Commun. 2017;8:15337.

41. Susin SA, Daugas E, Ravagnan L, Samejima K, Zamzami N, Loeffler M, et al. Two distinct pathways leading to nuclear apoptosis. J Exp Med. 2000;192:571-80.

42. Zanna C, Ghelli A, Porcelli AM, Martinuzzi A, Carelli V, Rugolo M. Caspase-independent death of Leber's hereditary optic neuropathy cybrids is driven by energetic failure and mediated by AIF and endonuclease G. Apoptosis. 2005;10:997-1007.

43. Susin SA, Lorenzo HK, Zamzami N, Marzo I, Snow BE, Brothers GM, et al. Molecular characterization of mitochondrial apoptosis-inducing factor. Nature. 1999;397:441-6.

44. Wsierska-Gadek J, Gueorguieva M, Wojciechowski J. MNNG induces dramatic DNA damage and non-apoptotic changes in cervical carcinoma HeLa cells. Ann N Y Acad Sci. 2003;1010:278-82.

45. Wesierska-Gadek J, Gueorguieva M, Schloffer D, Uhl M, Wojciechowski J. Nonapoptogenic killing of hela cervical carcinoma cells after short exposure to the alkylating agent $\mathrm{N}$-methyl- $\mathrm{N}^{\prime}$-nitro-N-nitrosoguanidine (MNNG). J Cell Biochem. 2003;89:1222-34.

46. Wangpu X, Yang X, Zhao J, Lu J, Guan S, Lu J, et al. The metastasis suppressor, NDRG1, inhibits "stemness" of colorectal cancer via downregulation of nuclear beta-catenin and CD44. Oncotarget. 2015;6:33893-911.

47. Hu N, Li ZM, Liu JF, Zhang ZZ, Wang LS. An overall and dose-response metaanalysis for thyrotropin and thyroid cancer risk by histological type. Oncotarget. 2016;7:47750-9.
48. Li ZM, Wu ZX, Han B, Mao YQ, Chen HL, Han SF, et al. The association between BMl and gallbladder cancer risk: a meta-analysis. Oncotarget. 2016;7:43669-79.

49. Artus C, Boujrad H, Bouharrour A, Brunelle MN, Hoos S, Yuste VJ, et al. AIF promotes chromatinolysis and caspase-independent programmed necrosis by interacting with histone H2AX. EMBO J. 2010;29:1585-99.

50. Cabon L, Galan-Malo P, Bouharrour A, Delavallee $L$, Brunelle-Navas MN, Lorenzo HK, et al. BID regulates AIF-mediated caspase-independent necroptosis by promoting BAX activation. Cell Death Differ. 2012;19:245-56.

51. Zhao H, Wang C, Lu B, Zhou Z, Jin Y, Wang Z, et al. Pristimerin triggers AlFdependent programmed necrosis in glioma cells via activation of JNK. Cancer Lett. 2016;374:136-48.

52. Liu Q, Mier JW, Panka DJ. Differential modulatory effects of GSK-3beta and HDM2 on sorafenib-induced AIF nuclear translocation (programmed necrosis) in melanoma. Mol Cancer. 2011;10:115.

53. Hanahan D, Weinberg RA. Hallmarks of cancer: the next generation. Cell. 2011;144:646-74.

54. Beroukhim R, Mermel CH, Porter D, Wei G, Raychaudhuri S, Donovan J, et al. The landscape of somatic copy-number alteration across human cancers. Nature. 2010;463:899-905.

55. Zhou T, Li G, Cao B, Liu L, Cheng Q, Kong H, et al. Downregulation of Mcl-1 through inhibition of translation contributes to benzyl isothiocyanate-induced cell cycle arrest and apoptosis in human leukemia cells. Cell Death Dis. 2013;4:e515.

56. Rapino F, Naumann I, Fulda S. Bortezomib antagonizes microtubule-interfering drug-induced apoptosis by inhibiting G2/M transition and MCL-1 degradation. Cell Death Dis. 2013;4:e925.

57. Nijhawan D, Fang M, Traer E, Zhong Q, Gao W, Du F, et al. Elimination of Mcl-1 is required for the initiation of apoptosis following ultraviolet irradiation. Genes Dev. 2003;17:1475-86.

58. Rahmani M, Davis EM, Bauer C, Dent P, Grant S. Apoptosis induced by the kinase inhibitor BAY 43-9006 in human leukemia cells involves downregulation of Mcl-1 through inhibition of translation. J Biol Chem. 2005;280:35217-27.

59. Maurer U, Charvet C, Wagman AS, Dejardin E, Green DR. Glycogen synthase kinase- 3 regulates mitochondrial outer membrane permeabilization and apoptosis by destabilization of MCL-1. Mol Cell. 2006;21:749-60.

60. Gao N, Kramer L, Rahmani M, Dent $\mathrm{P}$, Grant $\mathrm{S}$. The three-substituted indolinone cyclin-dependent kinase 2 inhibitor 3-[1-(3H-imidazol-4-yl)-meth-(Z)-ylidene]-5methoxy-1,3-dihydro-indol-2-one (SU9516) kills human leukemia cells via downregulation of $\mathrm{Mcl}-1$ through a transcriptional mechanism. Mol Pharmacol. 2006;70:645-55.

61. Chen R, Keating MJ, Gandhi V, Plunkett W. Transcription inhibition by flavopiridol: mechanism of chronic lymphocytic leukemia cell death. Blood. 2005;106:2513-9.

62. MacCallum DE, Melville J, Frame S, Watt K, Anderson S, Gianella-Borradori A, et al. Seliciclib (CYC202, R-Roscovitine) induces cell death in multiple myeloma cells by inhibition of RNA polymerase II-dependent transcription and downregulation of Mcl-1. Cancer Res. 2005;65:5399-407.

63. Alano CC, Ying W, Swanson RA. Poly(ADP-ribose) polymerase-1-mediated cell death in astrocytes requires NAD+depletion and mitochondrial permeability transition. J Biol Chem. 2004;279:18895-902.

64. Kang YH, Yi MJ, Kim MJ, Park MT, Bae S, Kang CM, et al. Caspase-independent cell death by arsenic trioxide in human cervical cancer cells: reactive oxygen speciesmediated poly(ADP-ribose) polymerase-1 activation signals apoptosis-inducing factor release from mitochondria. Cancer Res. 2004;64:8960-7.

65. Xu Y, Huang S, Liu ZG, Han J. Poly(ADP-ribose) polymerase-1 signaling to mitochondria in necrotic cell death requires RIP1/TRAF2-mediated JNK1 activation. J Biol Chem. 2006;281:8788-95.

66. Cuconati A, Mukherjee C, Perez D, White E. DNA damage response and MCL-1 destruction initiate apoptosis in adenovirus-infected cells. Genes Dev. 2003;17:2922-32.

67. Shimazu T, Degenhardt K, Nur EKA, Zhang J, Yoshida T, Zhang Y, et al. NBK/BIK antagonizes $\mathrm{MCL}-1$ and $\mathrm{BCL}-\mathrm{XL}$ and activates BAK-mediated apoptosis in response to protein synthesis inhibition. Genes Dev. 2007;21:929-41.

68. Yuste VJ, Moubarak RS, Delettre C, Bras M, Sancho P, Robert N, et al. Cysteine protease inhibition prevents mitochondrial apoptosis-inducing factor (AIF) release. Cell Death Differ. 2005;12:1445-8.

69. Ha HC, Snyder SH. Poly(ADP-ribose) polymerase is a mediator of necrotic cell death by ATP depletion. Proc Natl Acad Sci USA. 1999;96:13978-82.

70. Zong WX, Ditsworth D, Bauer DE, Wang ZQ, Thompson CB. Alkylating DNA damage stimulates a regulated form of necrotic cell death. Genes Dev. 2004;18:1272-82.

71. Holler N, Zaru R, Micheau O, Thome M, Attinger A, Valitutti S, et al. Fas triggers an alternative, caspase-8-independent cell death pathway using the kinase RIP as effector molecule. Nat Immunol. 2000;1:489-95.

72. Ben Sahra I, Laurent K, Giuliano S, Larbret F, Ponzio G, Gounon P, et al. Targeting cancer cell metabolism: the combination of metformin and 2-deoxyglucose induces p53-dependent apoptosis in prostate cancer cells. Cancer Res. 2010;70:2465-75. 